\title{
A Six-Step Online Teaching Method Based on Protocol-Guided Learning during the COVID- 19 Epidemic: A Case Study of the First Middle School Teaching Practice in Changyuan City, Henan Province, China
}

\author{
Ruichang Cai, Quanzhou Wang
}

The First Middle School of Changyuan City, Changyuan 453400, Henan, China

\begin{abstract}
The first Middle School in Changyuan City, Henan Province has been relying on protocol-guided learning for a long time. During the COVID-19 epidemic, the school used protocol-guided learning as a carrier and conducted online teaching activities based on an online teaching platform. We have created a six-step teaching method for students to learn independently during the epidemic. We explored this school's sixstep teaching method based on protocol-guided learning during the COVID-19 epidemic.
\end{abstract}

Best Evid Chin Edu 2020; 4(2):529-534.

Doi: 10.15354/bece.20.rp010.

Keywords: COVID-19 Epidemic; Online Teaching; Autonomous Learning; Teaching Practice; Middle School

About the Author: Ruichang Cai, Principal, Changyuan First Middle School, Changyuan 453400, Henan, China. Email: cyyzcrc@163.com.

Correspondence to: Quanzhou Wang, Vice Principal, Changyuan First Middle School, Changyuan 453400, Henan, China.Email: 13839066456@163.com.

Conflict of Interests: None. 
A UTONOMOUS learning refers to the ability of learners to set learning goals, determine learning content and progress, choose learning techniques, monitor

self-learning processes, and conduct self-assessment (Holec, 1981).

The first Middle School in Changyuan City, Henan Province, in recent years, has guided students in autonomous learning with protocol-guided learning. In the continuous practice, accumulation and improvement, a unique student autonomous learning model has been formed and achieved remarkable results.

Protocol-guided learning is based on curriculum standards and teaching materials for middle and elementary school teachers, combining students' academic situation and cognitive status, taking learning goals as the guidance, and questions as the core, and guiding students' learning before, during, and after class (Xia, 2020). Compared with the traditional teaching mode, teaching based on protocol-guided learning not only reflects the student as the center, but also significantly improves the academic performance of students, with an effect value of 0.29 (Zhou \& $\mathrm{Li}, 2020$ ).

During the COVID-19 epidemic, the first Middle School in Changyuan City, Henan Province, implemented the epidemic prevention and control requirements of the Ministry of Education and local governments. In response to the "School's Out, But Class's On" policy, i.e., "School is closed, but student learning is continuing online" or "Online Home Study" (This refers to the Official Website of the Chinese Ministry of Education: http://en.moe.gov.cn/), teachers and students throughout the school use protocol-guided learning as the carrier and online teaching platforms as the basis for online teaching activities to promote student autonomous learning. During the teaching process, the school resolutely and seriously implemented the teaching concept of "learning first and then teaching", combined with the way students learn independently during the epidemic, and created a six-step teaching method for online learning based on the teaching facts of the school.

\section{Teachers Assign Learning Tasks}

During the epidemic, the school strictly followed the normal teaching schedule to carry out autonomous learning activities for students. Restricted by the epidemic, the school adopted the "Internet + Protocol-guided Learning" teaching model and established public information exchange platforms such as WeChat group and Dingding group. In order to facilitate the communication and exchange between teachers, students and parents, teachers, students and parents are closely connected through the above public information communication tools.

Teachers will issue protocol-guided learning on established public information platforms (WeChat group or Dingding group). Teachers arrange learning tasks through the platform, students receive learning tasks on the platform, and parents urge students to accept tasks on the platform. 


\section{Students Prepare and Pre-Study According to the Protocol, Complete Homework and Communicate within the Group}

In the daily teaching activities, the school emphasizes "learning first and then teaching", and all students first preview the learning content and complete the corresponding preview test exercises. During the epidemic, students carried out autonomous learning activities based on tasks assigned by teachers on the platform.

When the teacher guides the students to preview, they mainly complete the "I. Self-learning the Basic Knowledge" part of the first lesson independently with "protocol-guided learning", or try to complete the questions in other parts of "protocol-guided learning" with pencils. On the platform, the independently completed preview exercises are uploaded to the study group, and discussions and exchanges are organized between group members.

\section{Parental Supervision and Teacher Guidance}

Parents are important guides for the growth of students. In the daily teaching, parents are too busy with work and are neglecting to educate and guide their children. Only when teachers and parents work together can we ensure that students' autonomous learning can be carried out smoothly during the epidemic, and that this" School's Out, But Class's On “will achieve its due effect (Zhang, 2020).

During the epidemic, parents were more with their students and more assumed some of the responsibilities that originally belonged to teachers. In order to give full play to the role of parents in educating students, the school puts forward different requirements for parents who work from home, parents who do not need to work at home, and teachers according to different personal circumstances.

If parents still have to undertake work tasks during the epidemic, they cannot always urge students to learn. Therefore, parents must put forward specific requirements to students every day, and strengthen the ideological education of students' autonomous learning, autonomous consciousness, and active learning. For parents who rest at home, there is more time to urge their children to learn independently. Parents not only see whether they learn or not, but also the efficiency of learning. They should pay attention to observe whether students can keep up with the teacher's teaching pace, and whether they can independently solve learning problems.

Students' autonomous learning also needs the guidance and guidance of teachers. On the one hand, teachers should check the group summary report in time to understand the students' autonomous learning situation. On the other hand, in response to students' problems and doubts during learning, teachers need to do timely telephone communication and guidance with parents.

\section{The Problem Feedback, Layer by Layer}


In the school's normal teaching practice, the school establishes six- or eight-person study groups to promote student learning through study groups. Each student has his or her own learning partner. Generally, students with higher grades and students with less than ideal grades go together in order to improve each other.

During the epidemic, the study group was transferred to a public information platform, connecting students, parents, and teachers through the public platform. And set up learning groups on the platform, each group has its own learning exchange group, to facilitate the team leader to monitor the completion of the group members' work in a timely manner. At the same time, the teacher can understand the learning situation of all students through the group leader, saving time.

Tasks and homework assignments arranged by the teacher are studied in groups. The detailed learning steps are below:

First, students think independently and digest the knowledge they can solve by themselves. In the process of self-study, outline the points you don't understand and communicate with your learning partners. If there are still problems after the exchange between the partners, submit them to the group, and the group will cooperate to solve them. In the WeChat group, the teacher collects the problems that the students can't solve in the study, and the problems that the students don't solve, the teacher focuses on explaining through the online platform.

For the team members to complete the task, the teacher asked the team leader to report in two groups in the class every day:

1. Report the housekeeping, physical exercise, and dual-channel temperature reports before 6:30 am in the morning.

2. Inform the list of students whose other tasks are not completed on time or not completed before 8:00 pm.

The above two periods of reporting require that you take notes and make a weekly summary every Sunday to announce your personal grade reduction. Therefore, we particularly emphasize that the class teacher should attach great importance to the training of the team leader and teach them management methods; at the same time, special care and guidance should be given in study and life.

\section{Teachers' Online Lecture Guidance, Problem Correc- tion and Re-Feedback}

Teachers learn about student group learning in a timely manner, and based on understanding of student learning, targeted teaching.

Teachers carry out online instructional activities based on the results of online learning and the learning of each group. Teachers' online classroom guidance must do three close integrations:

1. Closely integrate the "protocol-guided learning" of the school;

2. Closely integrate common questions raised in students' autonomous learning; 
3. Closely integrate high-quality course resources. High-quality teaching resources such as the "Henan Provincial Experimental Middle School Quality Online Course" were launched by the Education Department of Henan Province. We must pay attention to collecting the problems existing in the pre-class review, pay attention to intensive lectures and interaction with students. After the online teaching of science, the method of recording multiple small videos of the most difficult points and further focusing on counseling was provided to allow students to selectively check for omissions.

In order to ensure the pertinence of teaching, teachers who have already met the students will no longer teach.

\section{Consolidation and Promotion, Summary and Subli- mation}

The teacher arranges exercises for the students again through the network learning platform, and the students complete the corresponding exercises independently. After the students complete the homework, they submit it to the platform, and the teacher reviews it in time, and finds that the problem is corrected in time. Teachers guide students to summarize their learning content, so that students can refine the core knowledge of each lesson.

During the epidemic, the school guided students to learn independently through an original six-step method of online teaching. On the one hand, it responded to the national "School's Out, But Class's On" policy, which ensured the normal learning process of students and promoted the improvement of students' autonomous learning ability. On the other hand, it has further strengthened the communication with students' parents, strengthened the parents' awareness of students' supervision, and paved the way for the restoration of regular teaching activities.

\section{References}

Holec, H. (1981) Autonomy and foreign language learning. Oxford: Pergamon, 3.

Xia, J.P. (2020) Teaching for student learning: Exploration of teaching strategies based on protocol-guided learning. Sci Insigt Edu Front, 5(1): 451-467.
Zhang, M. "School's Out, But Class's On" requires the cooperation of many parties [N]. China Women's News, 2020-02-20 (001).

Zhou, L.J., Li, C.G. (2020) Can student selfdirected learning improve their academic performance? Experimental evidence from 
Cai \& Wang. A Six-Step Online Teaching Method during the COVID-19 Epidemic.

the instruction of protocol-guided learning in

China's elementary and middle schools. Sci
Insigt Edu Front, 5(1): 469-480.

Received: 29 February 2020

Revised: 03 March 2020

Accepted: 12 March 2020 